\title{
Remote Observations of Reentering Spacecraft Including the Space Shuttle Orbiter
}

\author{
Thomas J. Horvath (Thomas.J.Horvath@NASA.gov, 757-864-5236) \\ Melinda F. Cagle (Melinda.F.Cagle@NASA.gov, 757-864-7211) \\ NASA Langley Research Center, Hampton, VA 23681 \\ Jay H.Grinstead (Jay.H.Grinstead@NASA.gov, 650-604-6639) \\ NASA Ames Research Center, Moffet Field, CA 94035 \\ David M. Gibson (David.M.Gibson@jhuapl.edu, 240-228-1591) \\ Johns Hopkins University Applied Physics Laboratory, Laurel, MD 20723
}

\begin{abstract}
Flight measurement is a critical phase in development, validation and certification processes of technologies destined for future civilian and military operational capabilities. This paper focuses on several recent NASA-sponsored remote observations that have provided unique engineering and scientific insights of reentry vehicle flight phenomenology and performance that could not necessarily be obtained with more traditional instrumentation methods such as onboard discrete surface sensors. The missions highlighted include multiple spatially-resolved infrared observations of the NASA Space Shuttle Orbiter during hypersonic reentry from 2009 to 2011, and emission spectroscopy of comparatively small-sized sample return capsules returning from exploration missions. Emphasis has been placed upon identifying the challenges associated with these remote sensing missions with focus on end-to-end aspects that include the initial science objective, selection of the appropriate imaging platform and instrumentation suite, target flight path analysis and acquisition strategy, pre-mission simulations to optimize sensor configuration, logistics and communications during the actual observation. Explored are collaborative opportunities and technology investments required to develop a next-generation quantitative imaging system (i.e., an intelligent sensor and platform) with greater capability, which could more affordably support cross cutting civilian and military flight test needs.
\end{abstract}

\section{TABLE OF CONTENTS}

1. INTRODUCTION .1

2. Thermal IMAging (ShUTTLE ORBITER) .......2 3. EMISSION SPECTROSCOPY IMAGING (ENTRY

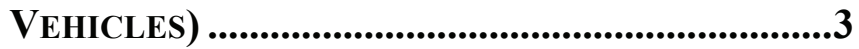

4. MISSION PLANNING ELEMENTS ..........................4

5. FUTURE CAPABILITY ..................................10

6. SUMMARY .....................................................11

REFERENCES..................................................11

BIOGRAPHY ............................................................16

\section{INTRODUCTION}

The design of high-speed aircraft, spacecraft and weapons systems is highly dependent on the use of simulation tools of varying fidelity. Following early trade studies using lowto-mid fidelity systems-level simulation tools, high fidelity computational fluid dynamics (CFD) simulations are then used to define the aero and aerothermal environment that a vehicle will experience during launch, sustained cruise and/or atmospheric reentry. Supporting the development and validation of these analytical and numerical toolsets are test data obtained in ground test facilities, such as hypersonic wind tunnels, shock tubes, and arc jets. As specialized as these facilities are, they cannot duplicate all of the pertinent aerodynamic and aerothermodynamic processes-even with multiple facilities and judicious experiment designs. Ground-based facility limitations coupled with recent systematic advancements in predictive capability have led some to forecast a time in the not so distant future where flight vehicles will be designed with an almost exclusive reliance on numerical methods. However, to benchmark, validate and assess the uncertainty of the simulation tools, flight-testing [1-3] of the integrated system will remain the premiere benchmark for the end-to-end vehicle design process. In addition, technologies directed at increasing quantitative data capture per flight are essential to insuring that the maximum return on investment is achieved during these flight tests.

Measurements obtained in relevant environments during actual flight are also crucial to monitor and verify operational vehicle health, identify and characterize unexpected phenomena and, if necessary, aid in anomaly resolution or risk assessment to the general public and environment. Historically, flight measurements employ insitu discrete sensors often referred to as Developmental Flight Instrumentation (DFI). Naturally, flight measurements of this nature come at the expense of added internal weight and complexity to the host vehicle and subsequent cost/schedule risk to the project. DFI weight and cost/risk challenges represent key impediments to collecting useful engineering flight data and why, despite six trips to Mars, the recent 2012 Mars Science Laboratory (MSL) mission represented the first time such a spacecraft had been equipped with sensors designed specifically to measure the performance of the heatshield during planetary entry, descent and landing (EDL). Until MSL, the lack of quality flight measurement has essentially bound NASA into Viking heritage technology and mass constraints for over thirty years [4]. Missed flight measurement opportunities have led to a successive line of spacecraft with overly conservative (i.e., heavier, costlier) thermal protection systems resulting in reduced operational/science 
capability.

NASA flight tests of instrumented spacecraft for earth entry at velocities at or above those required for lunar return have been few and were largely flown prior to the Apollo crewed flights - most notably Fire II [5, 6] and Apollo 4 [7, 8]. For atmospheric flight tests where vehicle recovery/reuse is not a requirement, DFI hardware investments are lost upon completion of the mission. When vehicle recovery is required, historical precedence suggests any DFI will be significantly reduced (or eliminated) when the vehicle is transitioned from a developmental to an operational status. A prime example is the NASA Space Shuttle program. After Space Shuttle Columbia's five developmental flights were completed, the extensive DFI sensor suite [9] was removed due to cost and weight penalties.

The purpose of this paper is to inform the flight test and research community of a maturing, quantitative in-flight measurement approach based upon remote observation and optical instrumentation. While it is acknowledged that inflight measurements derived from imagery will never completely replace the intrinsic value of traditional DFI, optical-based measurements do offer a complementary or in some cases an alternative opportunity to noninvasively obtain unique and critical flight data without interfering with nominal vehicle operations, weight, performance and project scheduling. If properly monitored, optical emissions radiating around and from a vehicle during launch or reentry because of high temperature gas or high surface temperature can provide insights into propulsion system operations, aerothermodynamic processes of atmospheric cruise or entry and thermal protection system (TPS) performance. To illustrate existing remote observation capability to acquire, analyze and use of imaging for scientific and engineering purposes, the present paper briefly summarizes several recent observation campaigns led by the NASA Langley (LaRC) and NASA Ames (ARC) Research Centers. These observations were- supported by aerial, ground and/or seabased platforms - and they offer a unique opportunity to compare and contrast the end-to-end challenges associated with the selection of the appropriate imaging platform and instrumentation suite selection, knowledge of the spacecraft flight path, pre-mission simulation for optimal sensor configuration, logistics and communications during the actual observation and the data acquisition process.

The benefits of scientific quality remote observations go well beyond simple photoraphic documentation and include correlation of critical flight events with on board instrumentation and flight anomaly reconstruction. Opportunities to develop a next-generation quantitative imaging system (i.e., integrated sensor and platform) to more affordably support civilian and military flight testing are discussed. Such a next generation imaging system could either directly or indirectly support developing critical and enabling technologies including elements necessary for (but not limited to) hypersonic aerothermodynamics, hightemperature materials for TPS, flight dynamics and range safety including launch, reentry and spacecraft demise (orbital debris). This next generation system might evolve from the large expensive military or civilian platforms used today, towards a smaller, more versatile system such as an up looking "intelligent sensor payload" integrated and optimized into an unmanned aerial system (UAS), or into a high altitude airship. In this long-range vision, sensor and platform are integrally connected. Sensor inputs would permit completely autonomous operations (i.e., no remote pilot).

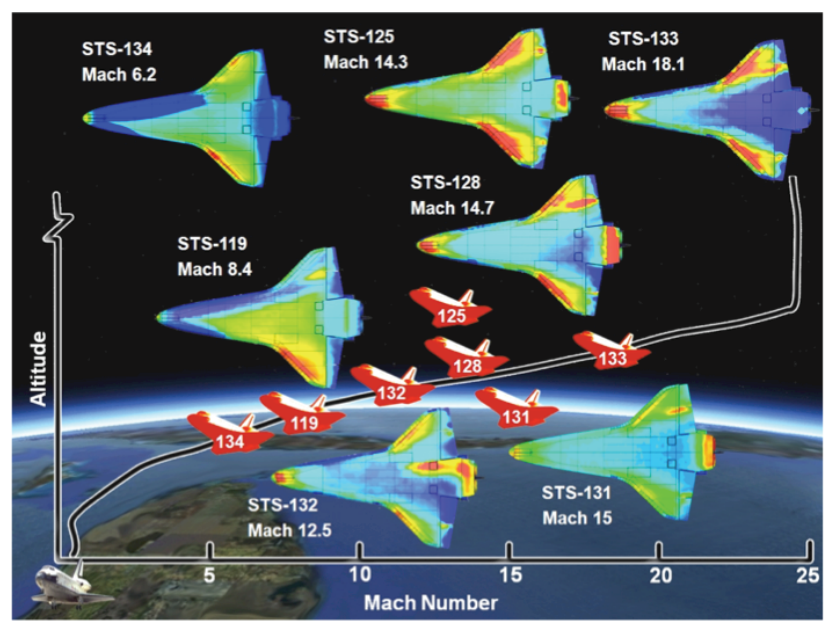

Figure 1 - Infrared images of the US Shuttle Orbiter during hypersonic reentry taken by NASA HYTHIRM. (color pallet varied to enhance detail on each flight)

\section{TherMAl IMAGING (ShUTTLE ORBITER)}

The NASA Hypersonic Thermodynamic Infrared Measurements (HYTHIRM) team utilized aerial and ground based infrared (IR) imaging systems to infer surface temperature distributions over the viewable windward surface of the Shuttle Orbiter during portions of hypersonic reentry [10-23]. The in-flight thermal imaging capability, discussed herein, represented several years of advocacy within the aerothermodynamics technical community [2438] The genesis of the HYTHIRM project and the use of optical systems to provide surface temperature was motivated by the Shuttle Columbia Accident Investigation (CAI) [39-40] and the subsequent Return-to-Flight (RTF) effort [41]. Per the recommendation of the CAI board, a suite of engineering tools was developed to determine the implications of a damaged TPS. A damaged TPS can induce local flow disturbances near the surface of the vehicle that can produce flow turbulence resulting in substantial (and potentially catastrophic) increases in surface temperature. Lack of quality flight data to calibrate and quantify the uncertainties with a boundary layer transition assessment tool resulted in an unprecedented and risky spacewalk during STS-114 to repair observed tile damage [42-43]. To lower risk posture for future flights, quantitative IR based global temperature measurements with adequate spatial resolution and dynamic range were proposed to non-intrusively complement the limited 
thermocouple coverage on the Orbiter [44-45]. Over a period of approximately the next 2.5 years, seven distinct infrared observations of the reentering Orbiter, spanning a Mach range from 6.2 to 18.1 , were made. Shown in Fig. 1 are surface temperature contours derived from these observations are shown in Fig. 1.

A majority of these observations were made over the Gulf

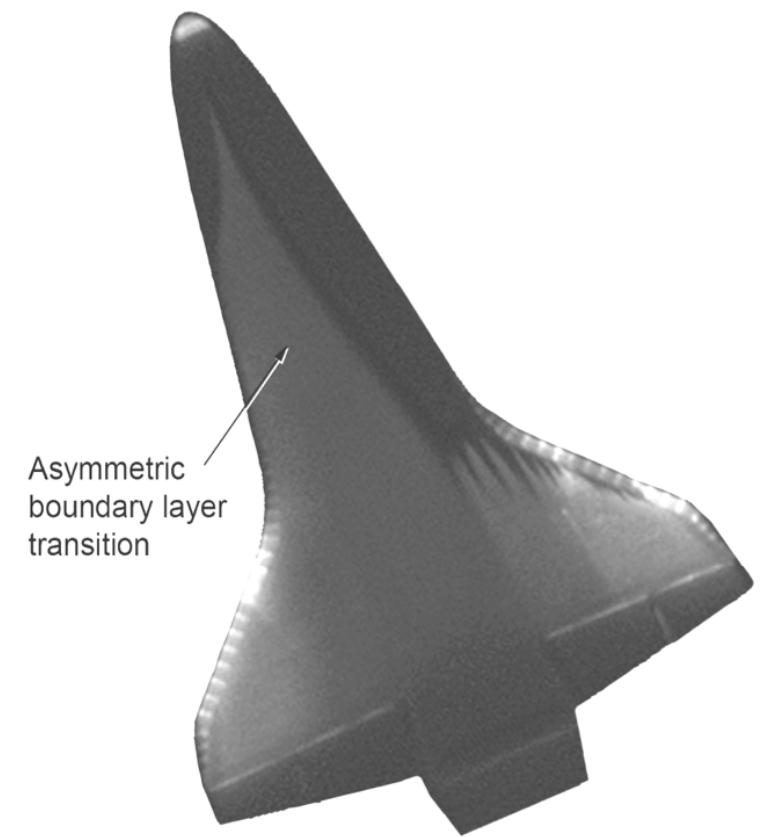

Figure 2 - Near infrared intensity image of Endeavour during STS-134 re-entry near the point of closest approach, Mach 5.8, Angle-of-Attack = 28.8 deg, Slant Range $\sim 32$ nautical miles

of Mexico with an aerial-based platform operated by the US Navy with an imaging system enhanced by NASA [12]. To the best of the author's knowledge, the 2011 Shuttle Orbiter infrared observations near Mach 18 (STS-133) represents the highest speed at which calibrated thermal imagery has been obtained on a crewed maneuvering vehicle in the Earth's atmosphere that has sufficient spatial resolution to delineate local temperatures differences at various locations on the vehicle surface. The most recent (and last) thermal imagery of an Orbiter during entry was acquired by a mobile ground-based optical system located on the west coast of Florida during Endeavour's final flight (STS-134) in 2011[23]. Time lapsed imagery from this ground near infrared (NIR) system revealed a phenomenon never before observed in flight - the actual development and forward progression of flow turbulence at hypersonic speeds on a global scale. In Fig. 2, a single still image captures the complex thermal footprints (higher temperature shown in lighter gray) associated with turbulent flow at the Orbiter surface. The time of appearance and the spatial extent of flow turbulence is crucial for an optimal TPS design [4647]. This particular image was acquired with the Shuttle located near the point of closest approach relative to the imaging system yielding a spatial resolution of approximately 4-inches per pixel. Distinct thermal gradients associated with the individual wing leading edge panels are readily observed. The success of the HYTHIRM team in acquiring quantitative surface temperature maps of the Orbiter windward surface was in large part due to development of a suite of mission planning tools [22] that facilitated the selection of the proper sensor configuration and the optimal location for viewing. The implications of proper planning and logistical advantages and disadvantages of the various imaging systems will be discussed in subsequent sections.

\section{EMISSION SPECTROSCOPY IMAGING (ENTRY VEHICLES)}

The NASA Ames Research Center and the SETI Institute have collaborated on the airborne observation of several spacecraft reentries. Unlike HYTHIRM's focus on spatially resolved thermal imaging, the Ames-SETI efforts primarily focused on emission spectroscopy of comparatively small-sized sample return capsule (SRC)

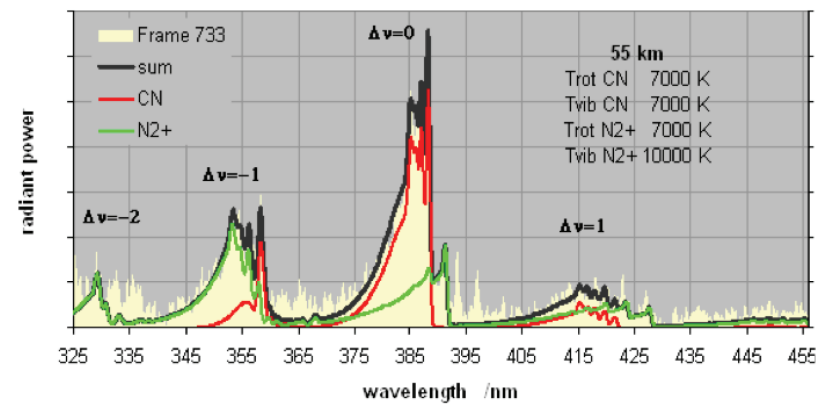

Figure 3 - Measured (yellow) and simulated (solid lines) emissions from the Stardust heatshield at an altitude of $\mathbf{3 4 . 2}$ miles

reentry vehicles returning extraterrestrial material from exploration missions. SRC's utilize ablative heat shield materials to absorb, transform, and reject high heating encountered at reentry velocities from lunar or interplanetary travel. These high reentry velocities also produce substantial shock layer radiation - and nonnegligible radiative heating when compared to reentry from low earth orbit. Thus, the primary objective of these observations was to obtain time-resolved measurements of absolute spectral radiance from the reentry capsule and its trailing wake. The data were analyzed to reveal quantities of importance to atmospheric reentry aerothermodynamics: apparent temperatures, shock radiation spectra from high temperature gases, ablation species spectra (if present), and their temporal evolution during reentry. The first successful collaboration was for NASA's Stardust in 2006 [48-60] followed by JAXA's Hayabusa in 2010 [61,62]. These reentry observation campaigns used aerial based imaging systems. 
Because to the small size of the SRC and the distance between the SRC and the observing aircraft (typically 100150 nautical miles), the imaging instruments on board the aircraft are generally unable to distinguish spatial distributions emitted from the SRC surface and surrounding gas radiation; the reentering $\mathrm{SRC}$ appeared to the instruments as a point source of light. Despite being spatially unresolved, the thermal (blackbody) emission from the heat shield surface was used to infer an apparent integrated surface temperature as a function of altitude. An example of spectral data recorded from the Stardust SRC just after reentry peak heating is compared with predicted emissions in Fig. 3. The spectrum in the near ultraviolet was acquired with a fiber-coupled slit spectrograph. The instrument was designed to capture emission from $\mathrm{N} 2+$ and $\mathrm{CN}$ at high resolution. When correlated to the reconstructed trajectory, these altitude-resolved measurements indicate the relative variations of shock radiation and ablation processes during reentry [48-60].

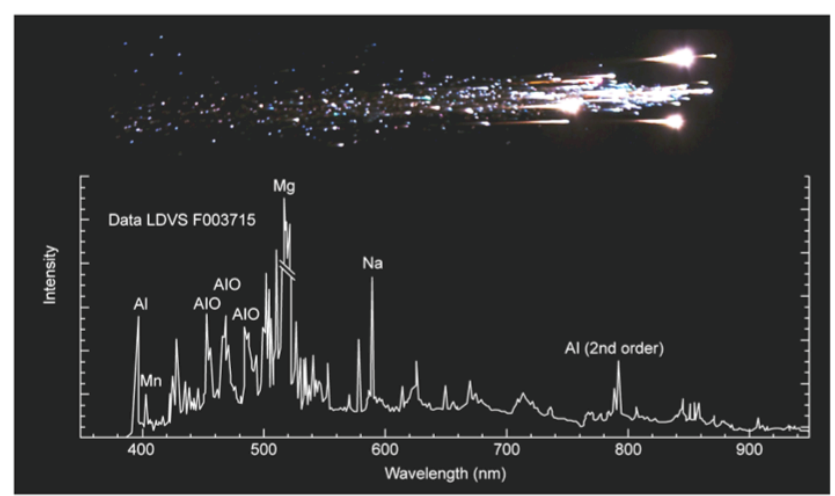

Figure 4 - Fragment spectrum from the Hayabusa spacecraft bus reentry disintegration identifying emission lines and bands of several chemical species

In comparison, the JAXA Hayabusa mission's return to Earth in 2010 resulted in a predicted but unintended combination of successful SRC capsule reentry and destructive reentry of the main spacecraft bus [61]. The Hayabusa mission suffered several system malfunctions that left the spacecraft without chemical propulsion and with only partial use of its ion thrusters. The lack of chemical propulsion prevented a planned spacecraft diversion maneuver after release of the SRC prior to reentry. Without the maneuver, the spacecraft bus followed the SRC into the atmosphere along the same trajectory. Although in close proximity, the SRC and spacecraft bus were sufficiently separated so that the airborne imaging instruments simultaneously captured both the SRC reentry and the unintended spacecraft bus breakup and disintegration. High-resolution spectroscopy instruments were able to spatially discriminate individual bus fragments for analysis. An example of an uncalibrated spectrum of one bus fragment is shown in Fig. 4, where several expected chemical species have been identified. These and similar data aid in understanding the complex thermal, structural, and aerodynamic processes that influence the destructive reentry of spacecraft and orbiting launch debris. With the eventual demise of the International Space Station (ISS), this type of quantitative imagery can improve analysis models used to compute debris dispersions that define hazard areas which is a key public safety issue.

\section{Mission PLANNING ELEMENTS}

While the NASA observation missions described in the previous sections had distinctly different imaging objectives and were performed and supported by separate organizations, they shared many common elements. Overall mission planning for these observations hinged on the successful integration of several disciplines, namely: aerothermodynamics, orbital mechanics, meteorology, optics, and systems engineering. In turn, these disciplines supported several inter-related elements of mission planning and project/technical risk management that include but are not limited to: trajectory analysis, asset selection and location, aircraft, ground and ship operations, weather forecasting, radiance modeling, instrumentation, logistics (e.g., airspace, communications, training) and data collection.

\section{Trajectory}

The LaRC and ARC imaging operations teams required reliable and timely information regarding their respective spacecraft trajectory for mission planning purposes. The teams utilized this information to conduct trade studies to obtain an optimized acquisition aircraft flight path solution that maximized signal quality, minimized risks with target acquisition and tracking, accommodated potential trajectory dispersions, and complied with other technical and geopolitical constraints. The LaRC and ARC imaging teams operated on a non-interference basis. That is, neither team was permitted to provide inputs to decisions that would have officially influenced the reentry flight path of the Orbiter or the SRC's. Trajectory information was provided to the LaRC and ARC imaging mission operations teams to support decisions on asset placement and tracking strategies. The reentry flight path and spacecraft orientation relative to the imaging systems were assessed by both teams using standard and custom trajectory analysis tools. The ARC-SETI team employed the use of TRAJ [63] a trajectory analysis tool that provides both the entry path and the aeroheating environment which determines the appropriate sensor selection. TRAJ provides the SRC trajectory using a three-degree-of-freedom simulation with appropriate gravitational, atmospheric and aerodynamic models. The entry state vector for the SRC vehicles was generally pre-determined well in advance of reentry. The crippled Hayabusa capsule however, required the NASA Jet Propulsion Laboratory (JPL) to provide multiple reentry state vector updates based on performance of "corrective" burns with the ion thrusters. These updates were critical in the re-tailoring of the flight path flown by the imaging aircraft. 
Because of the greater operational flexibility of the Shuttle Orbiter, reentry trajectory determination was more complex. Compared to the generally pre-determined reentry path of the SRC's, the Orbiter's reentry path was dependent on the earth-relative position of the Orbiter at the time of Space Station undock. Factors that affected this position included the launch date, duration of the mission and the crew timeline. It was not unusual for the Orbiter's mission

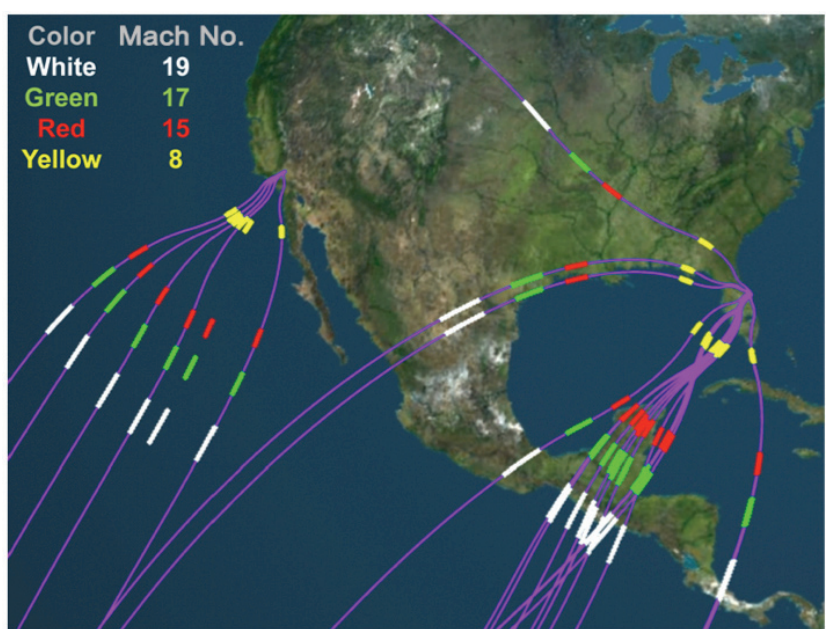

Figure 5 - A myriad of possible Shuttle entry trajectories into KSC or EDW returning from the International Space Station (ISS). Colors represent Mach number during reentry.

duration to be extended after the vehicle was on-orbit. The mission duration set the time for the nominal de-orbit burn which then determined the entry state vector. Weather permitting, reentry was usually initiated two days after the Orbiter undocked from the ISS. During the glide to the recovery location at either NASA Kennedy Space Center (KSC, primary) or Edwards Air force Base (EDW, secondary), the Orbiter performed a series of roll-bank maneuvers to manage energy. Reliably predicting the orientation of the bottom of the Shuttle relative to the imaging asset during these maneuvers is critical. A graphical-based simulation tool, Virtual Diagnostics Interface (ViDI) [64-67] was used to evaluate the anticipated Orbiter ground track and the Orbiter's orientation. Ground track changes because of on-orbit extensions or recovery site diversion from KSC (Florida) to EDW (California) are plotted in Fig. 5 using the ViDI tool. Given the importance of the trajectory to HYTHIRM imagery collection, it was essential to understand how the trajectory was derived and how it changed up to and including the few minutes just after the Orbiter performed its de-orbit burn to initiate reentry.

Lessons learned-The reentry trajectory was the most critical piece of information in planning and executing an observation of a reentering spacecraft. The anticipated flight path and vehicle orientation ultimately determined the physical location of the imaging system and drove constraints associated with political borders, air traffic control, flight hours, ground travel and mobile telescope basing, ship ports of call, and determined likely weather patterns to be encountered at the observation sites. In an early imaging attempt where no advance planning tools were available, supporting aircraft were not provided a trajectory update normally issued two hours before landing. Consequently, the Orbiter flew almost directly overhead precipitating telescope gimbal lock (loss of pointing ability) and subsequent loss of signal [33].

\section{Asset Selection}

Ultimately, the choice of an optical system is determined by the nature of the imaging requirements that in turn, drive the asset location. A majority of the high-speed science objectives of the NASA observations required deployment of the imaging system to locations over water thus precluding ground systems. Imaging platform strategies tend to favor the flexibility and range of airborne systems. The two primary aerial platforms used by the NASA imagery teams are shown in Fig. 6. The NASA DC-8 has a range of approximately 5,400 miles, an endurance time of up to 12 hours and a service ceiling of $41,000 \mathrm{ft}$. In contrast, the Navy P-3 has a range of approximately 4,000 miles, an endurance time of up to 12 hours and a service ceiling of $30,000 \mathrm{ft}$. The aircraft are used extensively by their organizations for earth/atmospheric science and missile defense, respectively. These aircraft can generally operate above cloud level and the attenuating effects of water and aerosols in the atmosphere. Naturally, they can be positioned closer to the intended target further mitigating detrimental atmospheric effects. Lastly, both multi-engine aircraft routinely support over-water operations and are more responsive to reasonable changes in the target vehicle ground track. Primary weaknesses of the airborne-based systems include diffraction limit induced blurring associated

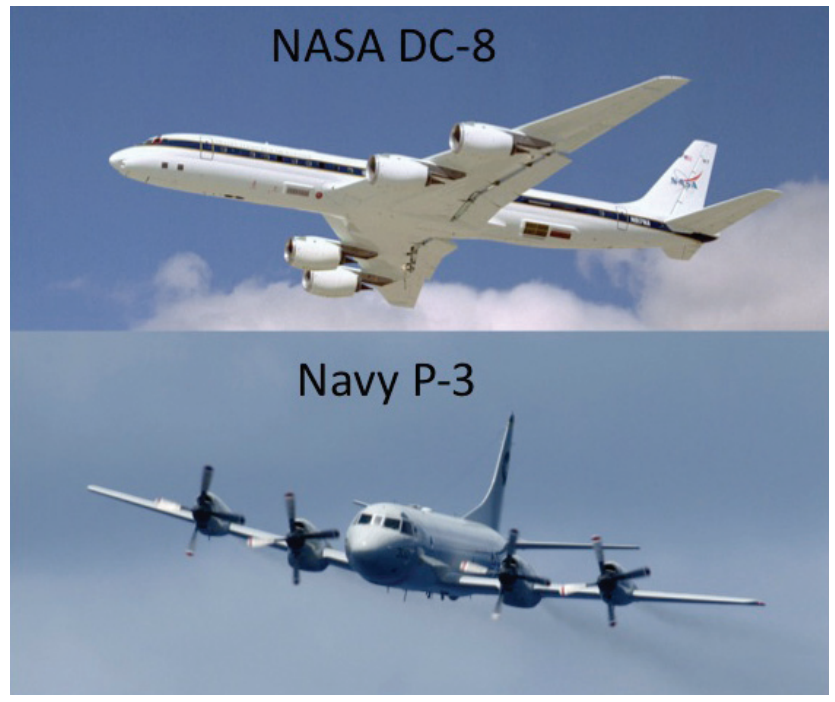

Figure 6 - Aircraft supporting NASA observations. (Upper) NASA DC-8-72 Airborne Laboratory based at Palmdale, CA. (Lower) Navy "Cast Glance" NP-3D Orion based at Pt. Mugu, CA. 
with small window apertures, image degradation from optical bench motions, structural resonance and/or local cavity-induced flow turbulence from optical housing. Programmatically, the relatively high operational expense of a large aircraft generally prohibits support to small flight test programs with limited resources. Schedule conflicts often develop from other programs competing for the use of a shared or "rented" aerial asset.

For land-based systems, the advantages include lower operational expense and large aperture/long focal length optics for improved spatial resolution. Commercially operated land-based imaging systems do not appear to be as susceptible to schedule conflicts. Weaknesses include long atmospheric path lengths, increased vulnerability to weather (below cloud level and moisture), inability to support large deviations in the target vehicle flight path (with a single system), and logistical considerations (e.g., system weight, availability of access roads, system security and power generation).

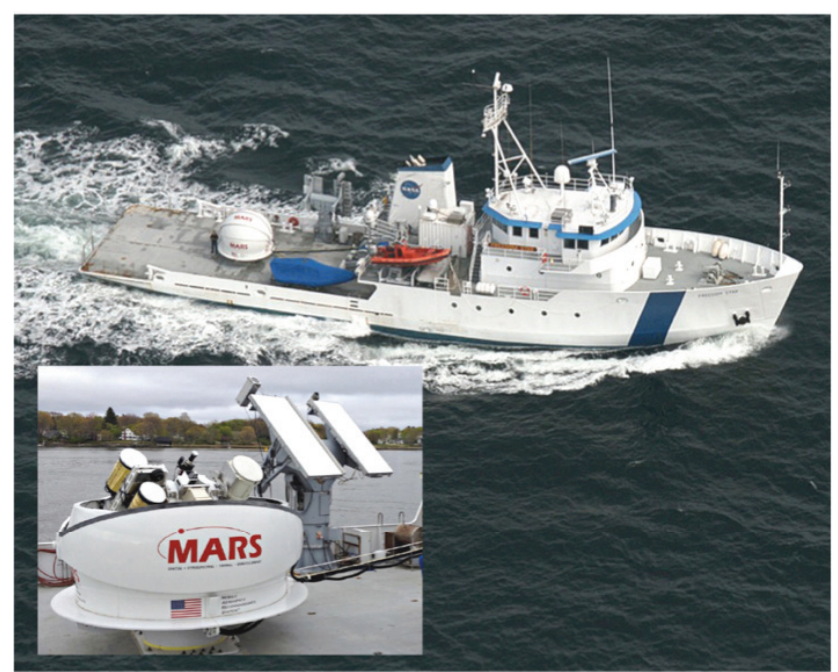

Figure 7 - Gyro-stabilized imaging system on Freedom Star. Inset: Optical systems within an environmental protective dome in proximity to $\mathrm{X}$-band radar used to provide pointing instructions during observation

In addition to the airborne and land-based systems, in 2012 the NASA LaRC imaging team enabled a new sea-based capability [68] on NASA's Freedom Star, a vessel formerly used to recover the Shuttle solid rocket booster hardware. A gyro-stabilized tracking mount and long focal length optics was successfully mounted onto Freedom Star's aft deck by a commercial entity as shown in Fig. 7. A specialized protective dome was required to shield the imaging systems against the harsh conditions at sea. NASA's Commercial Orbital Transportation Services (COTS) office desired imaging to aid in verification of the Falcon 9 performance during key events on ascent, including release of the Dragon capsule and solar panel deployments. The latter events necessitated the deployment of Freedom Star to the North Atlantic, just off the coast of Nova Scotia.
Lessons learned-Aerial based imaging systems offer many distinct advantages. Operating at altitudes above 40,000 ft, obscuring cloud coverage is essentially avoided and optical absorption from water vapor and scattering from aerosols is greatly diminished. Operations conducted at lower altitudes (including ground or sea level) were more susceptible to weather systems and often compromised science objectives or prevented data capture all together. Window constraints on aircraft generally set aperture size and limit spatial resolution performance (i.e., diffraction limit). Ground based systems have demonstrated superior spatial resolution performance and some level of mobility but experience has shown they are still very susceptible to longer atmospheric path lengths, turbulence near the ground and obscuring clouds. Sea based imaging systems inherently possess all the challenges of a ground system and more. In addition to making an observation through a marine layer, pointing stability requirements at sea associated with the narrow field of view optics represents a significant integration challenge in terms of gyro-stabilization and isolation from the ship motion and engine vibrations. The LaRC ship based observation of the Falcon 9 rocket during ascent was not successful due to adverse weather (clouds) that developed at the observation site hours just before the launch.

\section{Weather Forecasting}

Long-range weather forecasting is necessary to evaluate asset deployment options. Knowledge of the expected local conditions near the time of observation is required to mitigate the likelihood of clouds obscuring the desired view. The National Weather Service Spaceflight Meteorology Group [69] (SMG) located at the NASA Johnson Space

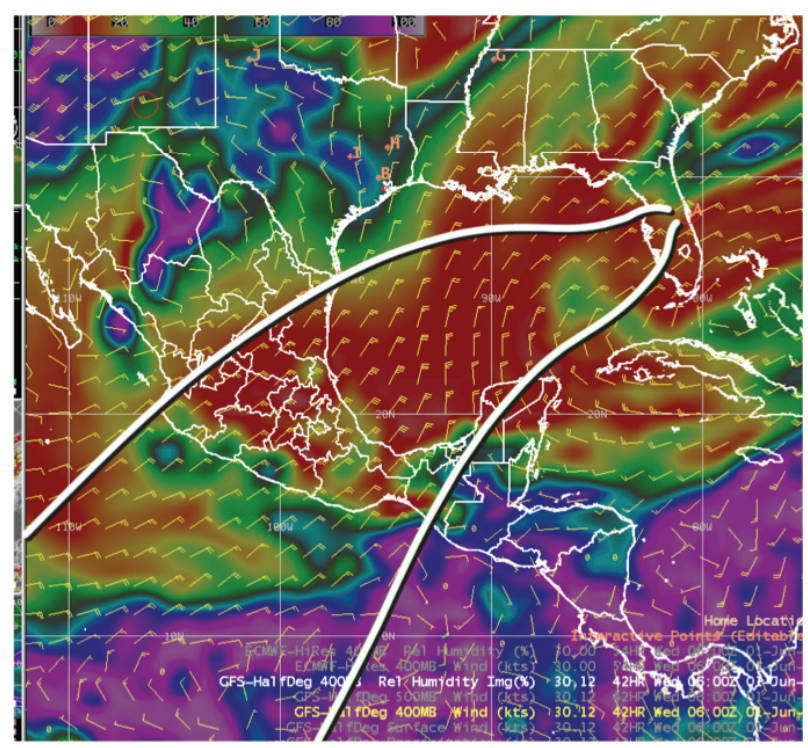

Figure 8 - STS-134 Shuttle Orbiter reentry groundtracks to KSC superimposed on predicted cloud cover forecast. Red corresponds to low relative humidity (no cloud cover); Green medium relative humidity (some cloud cover); Purple high relative humidity (high cloud cover). 
Center provided forecasting support to the LaRC and ARC imaging teams. Months in advance of an anticipated observation, SMG provided worldwide historical satellite cloud and water vapor climatology data and expected sea state conditions to assess the viability of potential observation locations. Monthly cloud cover data provided an outlook of expected impacts on HYTHIRM operations throughout the Gulf of Mexico, Central America and the Pacific just off the coast of California. SMG also assisted the ARC imaging team by providing weather forecasts for the region of South Australia where reentry of the Hayabusa SRC occurred. Naturally, such statistical cloud coverage information was more essential when ground or sea based platforms were being considered (or aerial systems with an operating ceiling below 25,000 ft).

For the short term forecasts when mission operations had commenced, SMG utilized a customized Advanced Weather Interactive Processing System (AWIPS) to superimpose Orbiter reentry tracks onto satellite imagery and numerical model forecast data (see Fig. 8). These graphics created highly effective weather visualization for rapid decisionmaking. When significant cloud coverage was encountered at the time of an observation, satellite information was used to determine an alternate imaging asset position that would present cloud free line of sight (CFLOS) to the target. A CFLOS software package developed by Johns Hopkins University Applied Physics Laboratory, infers cloud tops and bases from real time satellite measurements and indicates the level of obstruction by clouds along the line of sight from the observer to the target. If an obscured line of sight to the target was anticipated, a new observation position was identified and relayed to the asset personnel.

Lessons learned-Access to long-and short-range forecasts from professional meteorologists permitted the HYTHIRM imaging team to successfully anticipate any possible actions on the part of the Flight Director to alter the Orbiter's reentry path, particularly when weather was the key factor in the final de-orbit burn decision (i.e., on-orbit extension or diversion to an alternate recovery site). Graphics based briefings showing relevant weather conditions relative to the anticipated reentry path provided the HYTHIRM team the required flexibility to factor in the operational time needed to reposition an imaging system if required.

\section{Instrumentation}

A detailed discussion of instrument selection and configuration is beyond the scope of this overview paper. For a more comprehensive description of instrument layout for the distinctly different Shuttle Orbiter and SRC observations, the reader is referred to Refs. [11, 48, 61]. A basic instrument suite consisted of one or more science imagers and a target acquisition/tracking camera. The acquisition and tracking cameras are typically wide-field-ofview (WFOV) low-resolution charge coupled devices (CCD's), carefully bore-sighted to align with science imagers. Instrument viewports on the aircraft consisted of specialized windows constructed of optical quality material such as fused silica. Clear apertures of up to 16-in in diameter were available on the DC-8 (7-in diameter on the P-3). All instrument platform data acquisition systems had one or more methods to record time from a universal time code generator format (IRIG-B). Time codes were necessary to synchronize the imaging data streams with critical events occurring during the observation. Positional information to determine the distance between the asset and the spacecraft were obtained by global positioning satellites. Such estimates of optical path length are required to correct for atmospheric attenuation.

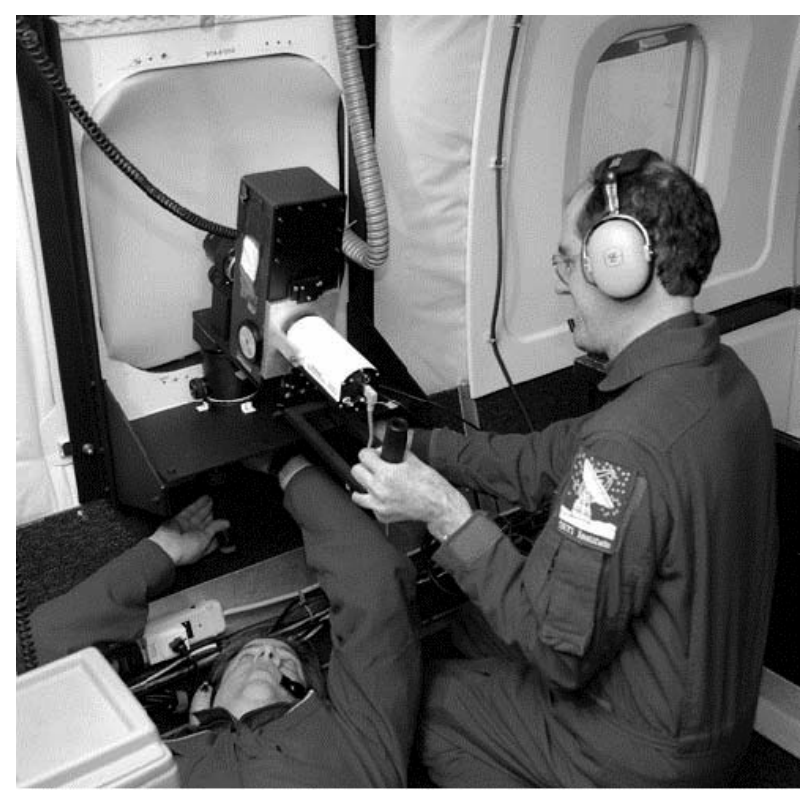

Figure 9 - One of several instrument stations in the NASA DC-8 that supported an SRC observation

The SRC observations from the NASA DC-8 employed up to 25 individual instruments with overlapping spectral ranges and other performance characteristics to mitigate against loss of data. Figure 9 illustrates a typical instrument setup in the NASA DC-8. Many instruments were slitless spectrographs that utilized transmission gratings. Other instruments employed fiber-coupled slit spectrographs or cameras with band-pass filters to realize spectral resolution. For the Hayabusa mission, spectral coverage was from the near ultraviolet through the short-wavelength infrared (up to $1670 \mathrm{~nm}$ ). Three instruments were devoted to highresolution color video from color-sensitive imaging arrays which yielded colored (rather than grayscale) images of the dispersed spectra.

In contrast, the quantitative observations of the Shuttle made from the P-3 "Cast Glance" aircraft involved the use of a single infrared detector optimized for the anticipated thermal measurement. The desired infrared emission range from the Orbiter was directed to the detector by a miniaturized, gyro-stabilized optical mirror and a long focal length lens. Initial evaluations of the Cast Glance legacy analog NIR camera indicated poor signal-to-noise ratio and insufficient dynamic range to accurately capture the expected emitted radiation from the Shuttle Orbiter during 
descent [12]. Because of this, the legacy analog imager was replaced with a digital CCD NIR camera with a spectral response of $400-1050 \mathrm{~nm}$ and a 1360 x 1024 focal plane array. A camera with identical specifications was later used during subsequent ground based observations.

Lessons learned-Acquisition of imagery using multiple sensors with overlapping capability is recommended to mitigate risk due to instrument failure. Also, with a single observation port, Cast Glance risk from instrument failure was mitigated by the construction of a backup sensor and companion acquisition computer.

\section{Simulation}

Several tools were used to identify and visualize spacecraft reentry parameters along with sensor response characteristics to make trades for informed decisions. The first suite of tools created high-fidelity, orientation-accurate synthetic images with the same pixel resolution as the actual imaging systems used by the assets. The second suite inferred anticipated optical emissions from the spacecraft during reentry. Collectively, these results were used extensively during pre-mission planning to tailor asset position, optimize sensor configuration and avoid over exposure (saturation) and loss of data.

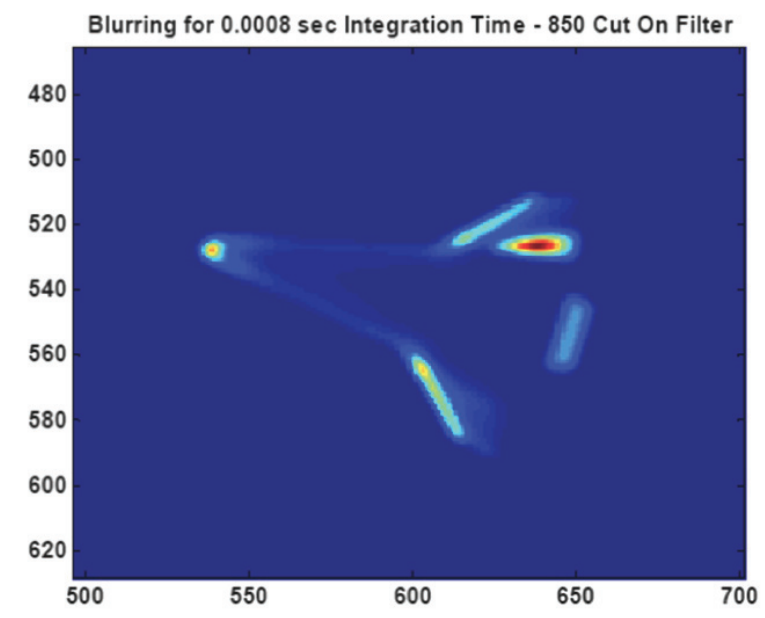

Figure 10a - Predicted Shuttle radiance

The ViDI tool developed at LaRC was to initially determine the optimum position of imaging asset(s) relative to the Shuttle Orbiter [22]. In this graphics based tool, surface CAD definition of the vehicle targeted for imaging and sixdegree-of-freedom trajectory information are imported into ViDI to visualize aspects of the entire trajectory on a virtual three-dimensional Earth. During a mission, a threedimensional Space Shuttle model was animated along the trajectory. The program allows the user to specify an imaging asset (e.g., a particular telescope mount on an aircraft or a land based system) and quickly determine the view/orientation of the Orbiter (or any vehicle) based on the asset position at any user specified point during reentry. Using this feature, multiple cameras placed at different viewing locations were used to assess trade-offs between constraints on the viewing angle, spatial resolution and time on target. The time accurate position of the Sun was also modeled to determine Sun exclusion constraints.

At the points of interest for the Shuttle Orbiter observations, radiance estimates were needed to provide the instrument operators pre-flight situational awareness pertaining to sensor response characteristics. A Missile Radiance Code (MSLRAD) [70] was adapted and used to model the optical signature from the Orbiter for any arbitrary orientation and in the waveband of interest (see Fig. 10a). MSLRAD utilizes material dependent optical properties accounting for spectral and angular variation as well as sensor spectral response behavior of the vehicle surface material. A standard MODTRAN package [71] was used to model the electromagnetic radiation propagation through the atmosphere and assess transmission losses between the imaging asset and the Orbiter. Sensor performance metrics were used to generate a 2-D intensity image simulating the anticipated detector response. Lastly, the synthetic radiometrically accurate image was artificially degraded with a point spread function to represent image degradation from expected optical and jitter induced motion and detector exposure time as shown in Fig. 10b. Pre-flight knowledge of this nature was extremely beneficial to the detector

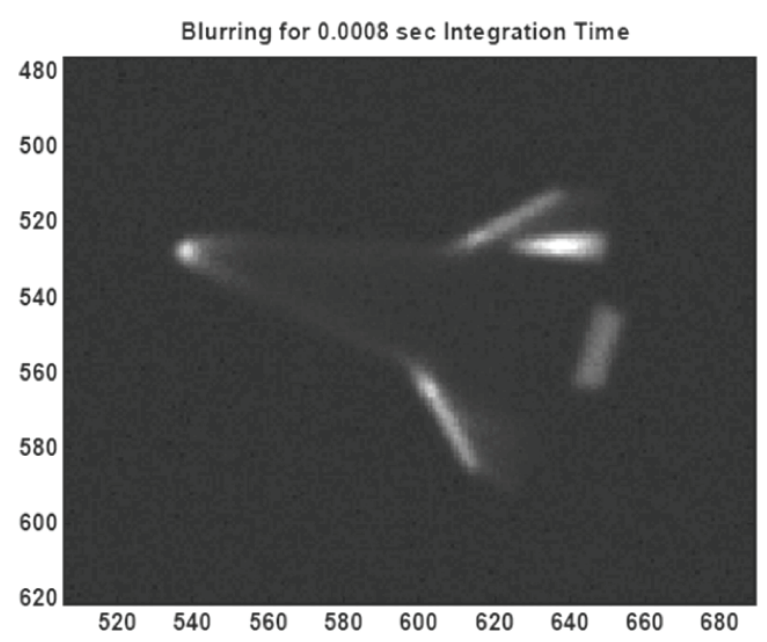

Figure 10b - Predicted NIR detector response

operators who were (in real time) adjusting the integration times manually to assure that the raw data would be collected in a manner that would span the sensor's maximum dynamic range, while mitigating against saturation.

In comparison, the much smaller SRC's descent through the atmosphere at higher velocities produced optical emission from the SRC's heatshield, the high temperature gases surrounding the vehicle, and gases, dust and ablation products in the vehicle's wake. The surface emission is thermal in origin and has an assumed graybody spectrum with magnitude characterized by the surface's temperature and emissivity. The gas emission originates from the excited states of atmospheric air species and other gas-phase species originating from heat shield ablation products 
injected into the vehicle's boundary layer. The extremely high temperatures of the gas between the shock wave and vehicle surface drives the population of these excited states. Wake radiation originates from species with long-lived excited states that have become entrained in the flow behind the vehicle. The excited states emit in discrete spectral lines and bands characteristic of their atomic or molecular structure. High fidelity computational tools [72-74] were exercised pre-flight to provide spectral simulations of the expected emissions. Atmospheric attenuation was estimated with MODTRAN.

Lessons learned-One of the most significant lessons learned from the NASA observations was the importance of mission specific planning tools for simulating detector response and optimally configuring the instrument parameters (i.e., gains, exposure times etc.) for reliable acquisition and tracking of the Shuttle Orbiter. Early attempts to image the Orbiter were largely unsuccessful [33] and were directly tied to the inability to accurately predict actual sensor response to the presented infrared signature. This initial radiance modeling capability was instrumental in underscoring the fact that the legacy analog NIR camera used by Cast Glance was inadequate. In early imaging attempts where no advance radiance modeling tools were available, an aircraft made an attempt to reposition for an unscripted high Mach number observation as the Orbiter reentered over Texas. Without advance situational awareness on the expected optical signature, the instrument operators were not successful in distinguishing the Orbiter from the horizon background with adequate time to acquire and track it, which resulted in complete loss of the remote imaging mission.

\section{Logistics}

Considerable pre-mission planning requiring the skills and precise communication between the mission operations team, the ground and flight crews, and the instrument operators enabled the successful LaRC and ARC observations. For the LaRC observations, the mission operations team consisting of personnel leading trajectory processing, communications and weather were co-located

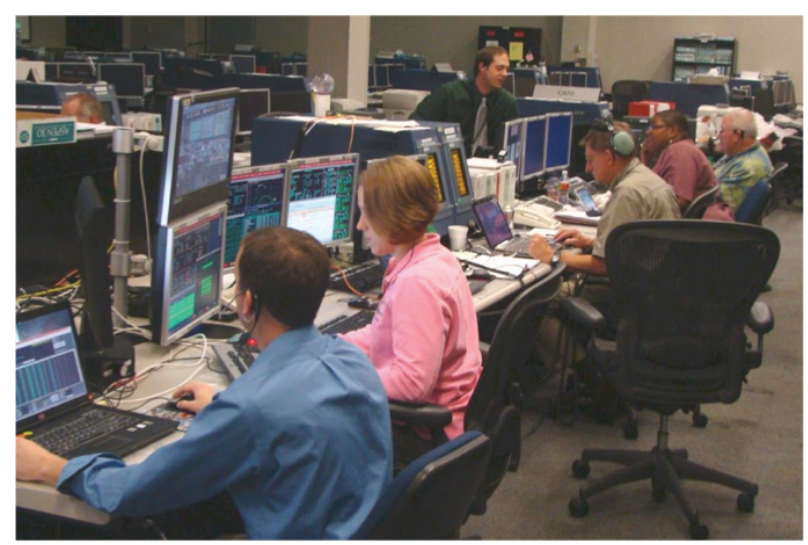

Figure 11 - LaRC imaging operations were coordinated from the auxiliary Space Shuttle Red Flight Control Room (FCR) at NASA JSC with a Shuttle Orbiter flight dynamics officer liaison, an asset representative, the science team lead and project management. Operations were conducted from one of the back up mission control rooms as shown in Fig. 11.

Science objectives of the observations were carefully balanced against aircraft or ship transit capabilities and onstation loiter times. In turn, asset range and loiter times were largely dependent upon projected weather and sea states. Long-range programmatic requirements ranged from the management of schedule, cost and technical risks to the negotiation for diplomatic clearances if flying into foreign airspace was anticipated (or military airspace if asset flight paths were in proximity to test ranges in the US and Australia). In order to facilitate coordination of air traffic clearances the LaRC imaging team stationed an experienced FAA controller with appropriate language skills in Mexican Air Traffic Control (ATC) facilities during mission execution.

A close relationship with the Space Shuttle flight directors and flight dynamics officers was essential for monitoring conditions of the Orbiter (propellant margins, orbit dispersions) and real time events (ISS re-boosts, undock and separation burns, orbit adjust burns to optimize de-orbit opportunities) that could impact the final Orbiter entry flight path. Long range, real-time communication was essential to pass last minute trajectory prediction updates and timing cues to the asset providers and instrument operators. References [22, 61] provide additional insight into the logistical planning process.

Ground-based observations with mobile assets created additional operational logistics. In most instances, the commercial ground-based asset owner was responsible for all ground transportation including transit to the initial deployment region and operating the instruments during the observation period. Advance coordination with local authorities within days of reentry was necessary to ensure adequate services (power, security etc.) and to identify the availability of unobstructed views. For these reasons, small airports were often considered for deployment. During STS-131 a ground-based imaging system was transported to observation sites often separated by hundreds of miles via a NASA UC-12 aircraft.

Lessons learned-Dress rehearsals were an important part of the training and risk mitigation process. When an aerial asset was involved it provided the mission operations team, flight crew and instrument operators the opportunity to rehearse procedures and become familiar with timing cues used during the actual mission. For the Hayabusa mission the dress rehearsal flight was conducted at night to allow the instrument operators to become familiar with the night sky star field in which the spacecraft was to appear. For Shuttle Orbiter operations, the aircraft flew into foreign airspace to exercise the processes of working foreign airspace requests with the appropriate airspace controllers. During the very first Orbiter observation with HYTHIRM, an issue with access to restricted airspace was quickly resolved because a similar scenario was rehearsed in an earlier training 
exercise. During dress rehearsal, each asset also simulated a data capture. For the aircraft, the camera operator worked closely with the pilot and aircrew to coordinate maneuvers in a pre-determined precision pattern to properly position the imaging windows for the data acquisition. Details of the flight path planning methodology for the two teams is described in detail in Refs. [11, 22]. The ground-based systems ran through a full hardware and software set up and a communications check with HYTHIRM control.

Integration of an imaging system to NASA's Freedom Star to support the launch of the inaugural SpaceX launch to the International Space Station proved to be a challenge to both the instrument operators and the ship's crew. Since the ship had never conducted imaging operations of this nature with precise pointing requirements, simple questions pertaining to how the optical tracking system would communicate with the companion tracking radar had to be addressed. Integration and verification of a stabilization system to compensate for the rolling and pitching motion of the ship proved difficult and time consuming. Design and construction of a system to suppress ship motor-induced vibrations was more complicated than expected. Enabling the large tracking system for viable ship-based operations took several months longer than anticipated. It is worth noting that while the ship's crew found sea states very benign, the observation team struggled to operate for weeks at sea due to physiological issues.

\section{FUTURE CAPABILITY}

\section{Autonomous Aerial System}

As discussed previously, imaging platform strategies tend to favor the flexibility and range of airborne systems, but existing crewed systems are inherently cost prohibitive. Drones (or high altitude airships) offer one potential path to realize the benefits of an airborne imaging platform at a more affordable cost. The leadership within the NASA Science Mission Directorate (SMD) has recognized that unmanned aircraft systems (UAS) have the potential to transform the way airborne science platforms contribute to earth science related investigations and environmental monitoring. The UAS application of the SMD is presently focused on enabling the use of autonomous aerial systems and advanced remote sensors to conduct earth science and atmospheric research. Most recently, a series of NASA Global Hawk flights from NASA Wallops Flight Facility (WFF) was initiated to begin a five-year mission specifically targeted to investigate the processes that underlie hurricane formation and intensity change in the Atlantic Ocean basin.

Expanding that innovation to include aeronautical research and acquisition of vehicle performance of future aerospace systems could enable a paradigm shift towards a reliable, flexible, affordable, less invasive process of maximizing the return-on-investment of NASA flight testing by complementing, enhancing or in limited cases, replacing the traditional in-situ DFI measurement approach.

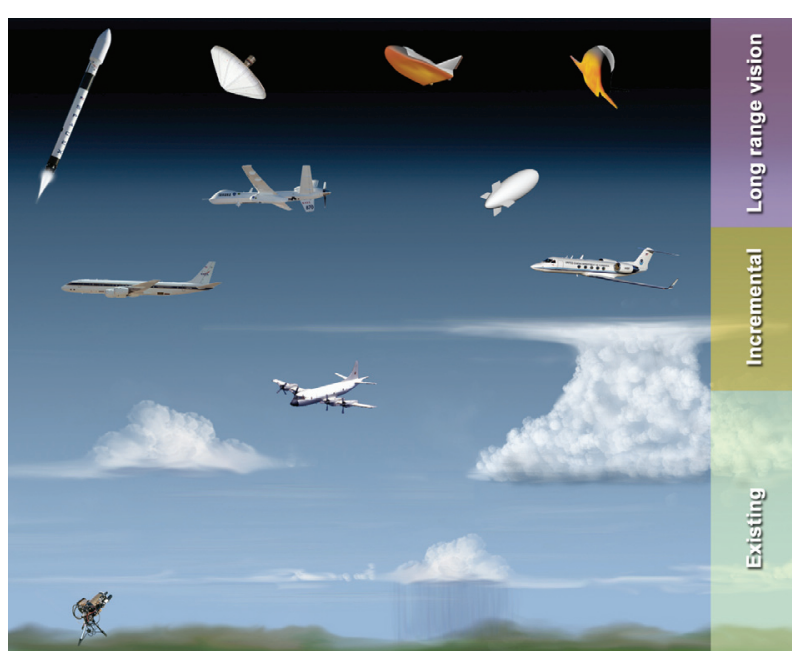

Figure 12 - Evolutionary autonomous and robotic imaging system to support flight test \& evaluation

As conceptually shown in Fig. 12, a truly affordable next generation system might evolve from the large expensive platforms used today toward a smaller, more versatile system; an up looking "smart sensor payload" with a UAS (or high altitude airship) optimally designed around it. In this long-range vision, sensor and platform are integrally connected. Sensor inputs would permit completely autonomous operations (i.e., no remote pilot) even in GPSdenied environments. Using intelligent flight controls and a payload-directed flight, this next generation imagery system would ultimately permit autonomous long-range target acquisition, tracking, image stabilization and enhancement, real-time sensor re-configuration for wave-band selection and aircraft attitude/orientation to optimize the data collection. Thus, this smart sensor payload would significantly increase mission flexibility while reducing operational costs. Because UAS are capable of longduration loitering, they are ideal for observations where there is uncertainty in mission timelines (i.e., launch or reentry delays). Because they are unmanned, UAS are also ideal for conducting operations in remote, dangerous or restricted airspace where there is risk to pilot and aircraft. As noted earlier, a high altitude capability places sensors well above the detrimental effects of the atmosphere. To better define UAS operational costs and develop a roadmap forward, NASA has initiated a system trade study. With the increasing use of unmanned drones for surveillance and reconnaissance missions, cooperation with and inputs from the sensor and optical community is actively sought to improve this trade study.

On a cost per pixel basis, the development of a small versatile robotic imaging system could enable an affordable imaging system that is competitive to a traditional DFI type temperature data collection architecture. One of the challenges with a remote imaging capability is the limited time the target vehicle is observed at spatially resolved conditions. Traditional in-situ surface or onboard measurements can be made continuously during re-entry or 
sustained flight. Existing capability with a single ground or aerial asset only permits observations of tens of seconds at meaningful spatial resolution. Multiple autonomous robotic imaging platforms positioned along the expected flight path could effectively extend observation times. This type of strategy would permit extended spatial coverage where uncertainties in the flight path are possible or expected, and enable distributed capability deployment, where vehicles can have varying sensor/manipulator capabilities to better achieve a broad range of objectives (i.e., visual, spectral, thermal). Such an aerial system would autonomously distribute required tasks amongst themselves based upon each vehicle's capabilities/sensor package and adapt to changes in the environment, learned knowledge associated with the phenomenology of the observation and mitigate failures on individual aerial platforms. The time horizon for a UAS based imaging system is imminent as there are significant ongoing national and international efforts to integrate UAS operations into sovereign airspace. It is now an opportune time to work UAS payload integration challenges.

\section{SUMMARY}

The flight measurement capability demonstrated by the NASA LaRC and ARC imagery teams has culminated in a high spatial and spectral resolution observations from ground, sea and aerial based imaging systems. These maturing capabilities suggest several opportunities for technical collaboration to advance modeling and instrumentation capabilities supporting flight test and evaluation and high speed research. The benchmark surface temperature maps of the Orbiter lower surface represent a rare and unique opportunity for collaborative comparison of advanced numerical predictive techniques focused on high Mach number laminar flow and hypersonic transition and turbulence modeling with in-flight global surface temperature maps. The emission data collected during the ARC SRC observations provide insight into the aerothermodynamic processes of atmospheric reentry and the performance of the capsule's thermal protection system.

Atmospheric reentry systems for NASA's future exploration missions, such as sample return from Mars, will rely on high-fidelity, physics-based design tools validated with relevant ground test and flight data. Validation enables researchers and engineers to build confidence in the use of these design tools, mature their development, and reduce risk in future heat shield designs. Collectively, success of the LaRC and ARC imaging teams confirm the viability of remote observation to support future development initiatives for reentry system and hypersonic technologies.

With targeted investments in optics, infrared sensor and imaging platform technologies, remote imaging could revolutionize developmental flight measurement technique leading to safer, affordable, and environmentally friendly access to and from space. Insights from the sensor and optics community are encouraged to evolve towards this next generation measurement capability.

\section{REFERENCES}

[1] Hallion, R. P., "The History of Hypersonics: or 'Back to the Future-Again and Again'," AIAA Paper 20050329, Jan. 2005.

[2] Kuntz, D. W., and Potter, D. L., "Boundary-Layer Transition and Hypersonic Flight Testing," Journal of Spacecraft and Rockets, Vol. 45, No. 2, 2008, pp. 184192.

[3] Blankson, I. M., and Pyle. J. S., "NASA's Hypersonic Flight Research Program"," AIAA Paper 1993-0308, Jan. 1993.

[4] NASA Space Technology Roadmaps and Priorities, Restoring NASA's Technological Edge and Paving the Way for a New Era in Space, Entry, Descent, and Landing Roadmap, Technology Area 09, Steering Committee for NASA Technology Roadmaps Aeronautics and Space Engineering Board Division on Engineering and Physical Sciences, Appendix L, The National Academies Press, Washington, D.C., 2012.

[5] Cauchon, D. L., "Project Fire Flight 1 Radiative Heating Experiment," NASA TM X-1222, 1966.

[6] Cauchon, D. L., "Radiative Heating Results from the Fire II Flight Experiment at Reentry Velocity 11.4 Kilometers per Second," NASA TM X-1402, 1967.

[7] Ried, Jr., R. C., Rochelle, W. C., and Milhoan, J. D., "Radiative Heating to the Apollo Command Module: Engineering Prediction and Flight Measurement," NASA TM X-58091, 1972.

[8] Lee, D. B., and Goodrich, W. D., "The Aerothermodynamic Environment of the Apollo Command Module During Superorbital Entry," NASA TN D-6792, 1972.

[9] Orbiter Experiments (OEX) Aerothermodynamics Symposium, NASA CP-3248 Part I, II., April 1995.

[10] Horvath, T. J., Tomek, D. M., Berger, K. T., Zalameda, J. N., Splinter, S. C., Krasa, P. W., Schwartz, R. j., Gibson, D. M., Tietjen, A. B., Tack, S., "The HYTHIRM Project: Flight Thermography of the Space Shuttle During Hypersonic Re-entry," AIAA-2010-241, January 2010.

[11] Tack, S., Tomek, D. M., Horvath, T. J., Verstynen, H. A., and Shea, E. J., "Cast Glance Near Infrared Imaging Observations of the Space Shuttle during Hypersonic Re-entry," AIAA Paper 2010-243, Jan. 2010.

[12] Zalameda, J. N., Horvath, T. J., Tomek, D. M., Tietjen, A. B., Gibson, D. M., Taylor, J. C., Tack, S., Bush, B. C., Mercer, C. D., and Shea, E. J., "Application of a Near Infrared Imaging System for Thermographic Imaging of the Space Shuttle during Hypersonic Reentry," AIAA Paper 2010-245, Jan. 2010.

[13] Gibson, D. M., Spisz, T. S., Taylor, J. C., Zalameda, J. 
N., Horvath, T. J., Tomek, D. M., Tietjen, A. B., Tack, S., and Bush, B. C., "HYTHIRM Radiance Modeling and Image Analyses in Support of STS-119, STS-125, and STS-128 Space Shuttle Hyper-sonic Re-entries," AIAA Paper 2010-244, Jan. 2010.

[14] Spisz, T. S., Taylor, J. C., Gibson, D. M., Kwame, O. W., Horvath, T. J., Zalameda, J. N., Tomek, D. M., Berger, Tietjen, A. B., Tack, S., and Schwartz, R. J., "Processing Near-Infrared Imagery of Hypersonic Space Shuttle Reentries," Thermosense XXXII Conference at 2010 SPIE Defense, Security, and Sensing Symposium, 5-9 April 2010, Orlando, FL, Paper 7661-17.

[15] Taylor, J. C., Gibson, D. M., Spisz, T. S., and Horvath, T. J., "Global Thermography of the Space Shuttle during Hypersonic Re-entry," AIAA Paper 2011-3324, June 2011.

[16] Spisz, T. S., Taylor, J. C., Gibson, D. M., Kennerly, S. W., Kwame, O., Horvath, T. J., Zalameda, J. N., Kerns, R. V., Shea, E. J., Mercer, C. D., Schwartz, R. J., Dantowitz, R. F., Kozubal, M. J., "Processing GroundBased Near-Infrared Imagery of Space Shuttle Reentries," Thermosense XXXIV Conference at 2012 SPIE Defense, Security, and Sensing Symposium, 2327 April 2012, Baltimore, MD, Paper 8354-15.

[17] Zalameda, J. N., Horvath, T. J., Kerns, R. V., Taylor, J. C., Spisz, T. S., Gibson, D. M., Shea, E. J., Mercer, C. D., Schwartz, R. J., Tack, S., Bush, B. C., and Dantowitz, R. F., "Thermographic Imaging of the Space Shuttle during Re-Entry Using a Near Infrared Sensor," Thermosense XXXIV Conference at 2012 SPIE Defense, Security, and Sensing Symposium, 2327 April 2012, Baltimore, MD, Paper 8354-14.

[18] Horvath, T. J., Kerns, R. V., Jones, K. M., Grinstead, J. H., Schwartz, R. J., Gibson, D. M., Taylor, J. C., Tack, S., and Dantowitz, R. F., "A Vision of Quantitative Imaging Technology for Validation of Advanced Flight Technologies," AIAA-2011-3325, June 2011.

[19] Wood, W. A., Kleb, W. L., Tang, C. Y., Palmer, G. E., Hyatt, A. J., Wise, A. J., McCloud, P. L., "Comparison of CFD Predictions with Shuttle Global Flight Thermal Imagery and Discrete Surface Measurements," AIAA Paper 2010-454, Jan. 2010.

[20] Candler, G. and Campbell, C., "Hypersonic Navier Stokes Comparisons to Orbiter Flight Data," AIAA Paper 2010-455, Jan., 2010.

[21] Vollmer, M., and Mollmann, K. -P., "Infrared Thermal Imaging - Fundamentals, Research and Applications," WILEY-VCH, Verlag GmbH \& Co., Weineim, Germany, 2010.

[22] Schwartz, R. J., McCrea, A. C., Gruber, J. R., Hensley, D. W., Verstynen, H. A., Oram, T., Berger, K. T., Splinter, S., Horvath, T. J., and Kerns, R. V., "Remote Infrared Imaging of the Space Shuttle During Hypersonic Flight: HYTHIRM Mission Operations and
Coordination," AIAA Paper 2011-3326, June 2011.

[23] Horvath, T. J., Zalameda, J. N., Wood, W. A., Berry, S. A., Schwartz, R. J., Dantowitz, R. F., Spisz, T. S., and Taylor, J. C., "Global Infrared Observations of Roughness Induced Transition on the Space Shuttle Orbiter," RTO-MP-AVT-200 Hypersonic LaminarTurbulent Transition, NATO AVT Business Week, Paper 27, April 2012, San Diego, CA.

[24] Blanchard, R.C., Wilmoth, R.G., Glass, C.E., Merski, N.R., Berry, S.A., Bozung, T.J., Tietjen, A., Wendt, J., and Dawson, D., "Infrared Sensing Aeroheating Flight Experiment: STS-96 Flight Results," Journal of Spacecraft and Rockets, Vol. 38, No.4, 2001, pp.465472.

[25] Blanchard, R.C., Anderson, B.A., Welch, S.S., Glass, C.E., Berry, S.A., Merski, N.R., Banks, D.W., Tietjen, A., and Lovern, M., "Shuttle Orbiter Fuselage Global Temperature Measurements from Infrared Images at Hypersonic Speeds," AIAA Paper 2002-4702, August, 2002.

[26] Berry, S.A., Merski, N.R., and Blanchard, R.C., "Wind Tunnel Measurements of Shuttle Orbiter Global Heating with Comparison to Flight," AIAA Paper 2002-4701, August, 2002.

[27] Throckmorton, D.A., Zoby, E.V., and Kantsios, A.G., "Shuttle Infrared Leeside Temperature Sensing (SILTS) Experiment," AIAA Paper 85-0328, January, 1985.

[28] Chocol J. C., "Infrared Imagery of Shuttle (IRIS)," Martin Marietta Corporation Final Report, MCR-76564, Contract NAS2-9381, August, 1977.

[29] "Infrared Imagery of Shuttle (IRIS) Experiment," IRIS/STS-3 Engineering Report, NASA-CR-193052, NASA AMES Research Center, June, 1982.

[30] Green, M.J., Budnick, M.P., Yang, L., and Chiasson, M.P., "Supporting Flight Data Analysis for Space Shuttle Orbiter Experiments at NASA Ames Research Center," AIAA Paper 83-1532, June, 1983.

[31] Horvath, T. ., Berry, S. ., Alter, S., Blanchard, R., Schwartz, R., Ross, M., and Tack, S., "Shuttle Entry Imaging Using Infrared Thermography," AIAA-20074267, June 2007

[32] Horvath, T., Berry, S., Splinter, S., Daryabeigi, K., Wood, W., Schwartz, R., and Ross, M., "Assessment and Mission Planning Capability For Quantitative Aerothermodynamic Flight Measurements Using Remote Imaging," AIAA-2008-4022, June 2008.

[33] Horvath, T. ., Berry, S. ., Alter, S., Blanchard, R., Schwartz, R., Ross, M., and Tack, S., "Shuttle Entry Imaging Using Infrared Thermography," AIAA-20074267, June 2007

[34] Horvath, T., Berry, S., Splinter, S., Daryabeigi, K., Wood, W., Schwartz, R., and Ross, M., "Assessment and Mission Planning Capability For Quantitative Aerothermodynamic Flight Measurements Using Remote Imaging," AIAA-2008-4022, June 2008. 
[35] Berry, S., Horvath, T., Schwartz, R., Ross, M., Campbell, C., Anderson, B., "IR Imaging of Boundary Layer Transition Flight Experiments," AIAA-20084026, June 2008.

[36] Splinter, S., Daryabeigi, K., Horvath, T., Mercer, C.D., Ghanbari, C., Tietjen, A., Schwartz, R., "Solar Tower Experiments for Radiometric Calibration and Validation of Infrared Imaging Assets and Analysis Tools for Entry Aero-Heating Measurements," AIAA2008-4025, June 2008.

[37] Schwartz, R., Ross, M., Baize, R., Horvath, T., Berry, S., Krasa, P., "A System Trade Study of Remote Infrared Imaging for Space Shuttle Re-entry," AIAA2008-4023, June 2008.

[38] Ross, M., Werner, M., Mazuk, S., Blanchard, R., Horvath, T. ., Berry, S. ., Wood, W., and Schwartz, R., "Infrared Imagery of the Space Shuttle at Hypersonic Entry Conditions," AIAA-2008-0636, 46th AIAA Aerospace Sciences Meeting and Exhibit, Reno, NV, Jan. 7-10, 2008

[39] Columbia Accident Investigation Board Final Reports, [online resource] URL:http:/caib.nasa.gov/. Vol. V, Appendix G.7, Starfire Team Final Report, NSTS37379, June 30, 2003.

[40] Columbia Accident Investigation Board Final Reports, [online resource] URL:http://caib.nasa.gov/. Vol. III, Appendix E.2, Image Analysis Team Final Report, NSTS-37384, June 30, 2003.

[41] Berry, S. A., Horvath, T. J., Cassady, A., Kirk, B. S., Wang, K.C., and Hyatt, A. J., "Boundary Layer Transition Results From STS-114,” AIAA-2006-2922, June 2006.

[42] Berry, S. A., Horvath, T. J., Greene, F. A., Kinder, G. R., and Wang, K. C., "Overview of Boundary Layer Transition Research in Support of Orbiter Return To Flight," AIAA-2006-2918, June 2006.

[43] Berry, S. A., King, R., Kegerise, M., Wood, W., McGinley, C., Berger, K., Anderson, B., "Orbiter Boundary Layer Transition Prediction Tool Enhancements," AIAA-2010-0246, Jan. 4-7, 2010.

[44] Campbell, C.H., Garske, M.T., Kinder, G, and Berry, S.A. "Orbiter Entry Boundary Layer Flight Testing," AIAA 2008-635, January 2008.

[45] Berger, K. T., Anderson, B., Campbell, C., Garske, M., Saucedo, M. Kinder, G., Micklos, A., "Boundary Layer Transition Flight Experiment Overview," AIAA Paper 2011-3323, June 2011.

[46] Wurster, K. E., "An Assessment of the Impact of Transition on Advanced Winged Entry Vehicle Thermal Protection System Mass," AIAA Paper 811090, June 1981.

[47] Lin, T. C., "Influence of Laminar Boundary-Layer Transition on Entry Vehicle Designs," Journal of Spacecraft and Rockets, Vol. 45, No. 2, 2008, pp. 165175.
[48] Jenniskens, P., "Observations of the STARDUST Sample Return Capsule Entry with a Slit-less Echelle Spectrograph," AIAA Paper 2008-1210, Jan., 2010.

[49] Stardust Hypervelocity Entry Observing Campaign Support," NASA Engineering and Safety Center Rept. RP-06-80, 31 Aug. 2006.

[50] Jenniskens, P., "Observations of the Stardust Sample Return Capsule Entry with a Slitless Echelle Spectrograph", Journal of Spacecraft and Rockets, Vol. 47, No. 6, pp. 718-735, 2010.

[51[ Liu, Y., Prabhu, D., Trumble, K. A., Saunders, D., and Jenniskens, P., "Radiation Modeling for the Reentry of the Stardust Sample Return Capsule", Journal of Spacecraft and Rockets, Vol. 47, No. 6, pp. 741-752, 2010.

[52] Rairden, R. L., and Jenniskens, P., "Near-Ultraviolet Spectroscopy of the Stardust SRC Reentry", Journal of Spacecraft and Rockets, Vol. 47, No. 6, pp. 753-756, 2010.

[53] Trumble, K. A., Cozmuta, I., Sepka, S., Jenniskens, P., and Winter, M., "Postflight Aerothermal Analysis of Stardust Sample Return Capsule", Journal of Spacecraft and Rockets, Vol. 47, No. 6, pp. 765-774, 2010.

[54] Harms, F., Wolf, J., Raiche, G., and Jenniskens, P., "Imaging and Slitless Spectroscopy of the Stardust Capsule Reentry Radiation", Journal of Spacecraft and Rockets, Vol. 47, No. 6, pp. 868-872, 2010.

[55] Jenniskens, P., Wilson, M. A., Winter, M., and Laux, C. O., " Resolved CN Band Profile of Stardust Capsule Radiation at Peak Heating", Journal of Spacecraft and Rockets, Vol. 47, No. 6, pp. 873-877, 2010.

[56] Taylor M. J., and Jenniskens, P., "Near-Infrared Spectroscopy of the Stardust Sample Return Capsule Entry: Detection of Carbon", Journal of Spacecraft and Rockets, Vol. 47, No. 6, pp. 878-883, 2010.

[57] Stenbaek-Nielsen, H. C. and Jenniskens, P., "HighSpeed Spectrographic Photometry of the Stardust Sample Return Capsule around Peak Deceleration", Journal of Spacecraft and Rockets, Vol. 47, No. 6, pp. 884-888, 2010.

[58] Wercinski, P. F., and Jenniskens, P., "Digital Still Snapshots of the Stardust Sample Return Capsule Entry", Journal of Spacecraft and Rockets, Vol. 47, No. 6, pp. 889-894, 2010.

[59] Jenniskens, P., Koop, M., and Albers, J., "Intensified Low-Resolution Optical Spectroscopy of the Stardust Sample Return Capsule Entry", Journal of Spacecraft and Rockets, Vol. 47, No. 6, pp. 895-900, 2010.

[60] Winter, M. W., and Trumble, K. A., "Near-Ultraviolet Emission Spectroscopy During an Airborne Observation of the Stardust Reentry", Journal of Spacecraft and Rockets, Vol. 48, No. 1, pp. 59-71, 2011. 
[61] Grinstead, J. H., Jenniskens, P., Cassell, A. M., Albers, J., and Winter, M. W., "Airborne Observation of the Hayabusa Sample Return Capsule Re-entry", AIAA Paper 2011-3329, June 2011.

[62] Cassell, A. M., Allen, Jr., G. A., Grinstead, J. H., Antimisiaris, M., Albers, J., and Jenniskens, P., "Hayabusa Reentry: Trajectory Analysis and Observation Mission Design”, AIAA Paper 2011-3330, June 2011.

[63] Allen, Jr., G. A.; Wright, M. J.; and Gage, P. J.: The Trajectory Program (Traj): Reference Manual and User Guide. NASA, TM-2004-212847, Mar. 2005

[64] Schwartz, R. J., McCrea, A. C., "Virtual Diagnostic Interface: Aerospace Experimentation In The Synthetic Environment," MODSIM World Conference and Expo., Oct., 14, 2009.

[65] Schwartz, R.J., "ViDI: Virtual Diagnostics Interface Volume 1-The Future of Wind Tunnel Testing" Contractor Report NASA/CR-2003-212667, December 2003.

[66] Schwartz, R.J., Fleming, G.A.,"LiveView3D: Real Time Data Visualization for the Aerospace Testing Environment", AIAA- 2006-1388, 44th AIAA Aerospace Sciences Meeting and Exhibit, Reno, Nevada, Jan. 9-12, 2006.

[67] Schwartz, R.J., McCrea, A.C., "Virtual Diagnostic Interface: Aerospace Experimentation in The Synthetic Environment", MODSIM World 2009 Conference and Expo, Virginia Beach, Virginia, Oct. 14-16, 2009.

[68] NASA Web site:

Www.nasa.gov/exploration/commercial/.../scifli.html

[69]NASA Web site: www.srh.noaa.gov/smg/

[70] Oguz, H. N. and O’Neil, J. M., "EZMSLRAD Users Manual," JHU/APL, A1C-04-067, 13 May 2004.

[71] Berk, A., Anderson, G. P., Bernstein, L. S., Acharya, P. K., Dothe, H., Matthew, M. W., Adler-Golden, S. M., Chetwynd, Jr., J. H., Richtsmeier, S. C., Pukall, B., Allred, C. L., Jeong, L. S. and Hoke, M. L., "MODTRAN4 Radiative Transfer Modeling for Atmospheric Correction, SPIE Proceeding," Optical Spectroscopic Techniques and Instrumentation for Atmospheric and Space Research III, Volume 3756 (1999).

[72] Chen, Y.-K., and Milos, F. S., "Fully Implicit Ablation and Thermal Analysis Program (FIAT)," Fourth International Conference on Composites Engineering (ICCE/4), edited by D. Hui, International Community for Composites Engineering and College of Engineering, Univ. of New Orleans, New Orleans, LA, pp. 661, 662, 1997.

[73] Milos, F. S., Chen, Y.-K., and Squire, T. H., "Updated Ablation and Thermal Response Program for Spacecraft Heat Shield Analysis," 17th Thermal and Fluids Analysis Workshop, Univ. of Maryland, Paper TFAWS06-1008, Aug. 2006.
[74] Whiting, E. E., Park, C., Liu, Y., Arnold, J. O., and Paterson, J. A., "NEQAIR96, Nonequilibrium and Equilibrium Radiative Transport and Spectra Program: User's Manual,” NASA Rept. 1389, Dec. 1996. 


\section{BIOGRAPHY}

Mr. Thomas J. Horvath is an aerospace engineer in the Aerothermodynamics Branch at the NASA Langley Research Center. His main area of research has been experimental aeroheating, providing

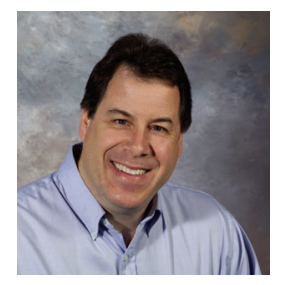
aerothermodynamic support for many recent NASA programs such as Shuttle, X-33, X34, X-37, X-38, X-43A, and Orion. Mr. Horvath has a B.S. in Physics from Ripon College and a M.S. in Aeronautics from George Washington University. He currently serves as Principle Investigator for the Scientifically Calibrated In-Flight Imagery (SCIFLI) team.

Ms. Melinda F. Cagle is a project manager in the Space Technology \& Exploration Directorate at NASA Langley Research Center. She has been involved with aerospace and earth science

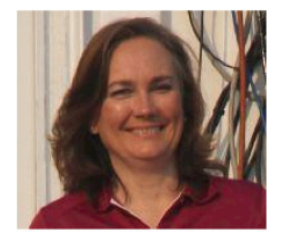
projects including the Ares I-X and the Cloud-Aerosol Lidar and Infrared Pathfinder Satellite Observation (CALIPSO) satellite. She currently serves as the project manager for the Scientifically Calibrated In-Flight Imagery (SCIFLI) team. Ms. Cagle has a B.S. in Mechanical Engineering and a M.S. in Industrial and Systems Engineering from Virginia Tech.

Dr. Jay Grinstead is an aerospace engineer in the Aerothermodynamics Branch at NASA Ames Research Center. He specializes in atmospheric entry physics, with an emphasis on experimental test methodologies and optical metrology. He serves as a project manager for agency and commercial space projects. He also participates in several international collaborations with European and Japanese partners. Dr. Grinstead received his Ph.D. in Mechanical and Aerospace Engineering from the University of Virginia in 1995. Dr. Grinstead held postdoctoral research positions at Princeton University and the National Institute of Standards and Technology prior to joining NASA in 2000.

Dr. David M. Gibson has 25 years of experience in ballistic missile defense (BMD) systems and phenomenologies; missile, space and tactical surveillance; and electro-optical sensors, observational techniques and data

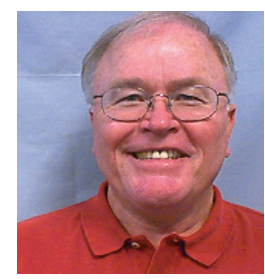
reduction. Currently Dr. Gibson is at the Johns Hopkins University Applied Physics
Laboratory (JHU APL). His efforts at the JHU APL have supported the Missile Defense Agency (MDA) and NASA's award-winning Hypersonic Thermal Infrared Measurements (HYTRHIRM) Program. Dr. Gibson has made observations in the electromagnetic radiation spectrum from the radio through the X-ray bands with recent emphasis on airborne infrared and LEO satellite sensors. He began his professional career as an astronomical researcher and university professor. More recently Dr. Gibson has served private industry and federally funded research centers as a scientist, technical manager and program manger. 